\title{
Comparing hypofractionated to conventional fractionated radiotherapy in postmastectomy breast cancer: a meta- analysis and systematic review
}

\author{
Lei Liư, Yongqiang Yang ${ }^{\dagger}$, Qi Guo ${ }^{\dagger}$, Bixin Ren, Qiliang Peng, Li Zou, Yaqun Zhu and Ye Tian ${ }^{*}$
}

\begin{abstract}
Purpose: To compare the efficacy and toxicity of hypofractionated radiotherapy versus conventional fractionated radiotherapy in postmastectomy breast cancer using meta-analysis.

Methods: The PubMed, EMbase, Cochrane Library, Google Scholar, Wan Fang and CNKI databases were searched to identify controlled clinical trials comparing hypofractionated radiotherapy versus conventional fractionated radiotherapy in postmastectomy breast cancer. Overall survival (OS) was the primary endpoint, and disease-free survival (DFS), locoregional recurrence (LRR), distant metastasis (DM), acute skin toxicity, acute lung toxicity, late skin toxicity, lymphedema, shoulder restriction, and late cardiac related toxicity were the secondary endpoints.

Results: Twenty-five controlled clinical trials involving 3871 postmastectomy breast cancer patients were included in this meta-analysis according to the selection criteria. The meta-analysis revealed that there were no significant differences in OS $(O R=1.08,95 \% C l=0.87 \sim 1.33, P=0.49)$, DFS $(O R=1.13,95 \% C l=0.91 \sim 1.40, P=0.28), \operatorname{LRR}(O R=$ $1.01,95 \% C l=0.76 \sim 1.33, P=0.96)$, DM $(O R=1.16,95 \% C l=0.85 \sim 1.58, P=0.34)$, acute skin toxicity $(O R=0.94,95 \%$ $C l=0.67 \sim 1.32, P=0.72)$, acute lung toxicity $(O R=0.94,95 \% C l=0.74 \sim 1.20, P=0.62)$, late skin toxicity $(O R=0.98,95 \%$ $C l=0.75 \sim 1.27, P=0.88)$, lymphedema $(O R=0.99,95 \% C l=0.77 \sim 1.28, P=0.94)$, shoulder restriction $(O R=0.75,95 \%$ $C l=0.43 \sim 1.31, P=0.31)$, or late cardiac related toxicity $(O R=1.17,95 \% C l=0.82 \sim 1.65, P=0.39)$ between the two groups.

Conclusions: The results of this study show that compared to conventional fractionated radiotherapy, hypofractionated radiotherapy is not significantly different with respect to efficacy or toxicity in postmastectomy breast cancer. Additional large randomized clinical trials are needed to further confirm this conclusion.
\end{abstract}

Keywords: Breast cancer, Hypofractionated radiotherapy, Conventional radiotherapy, Postmastectomy

\section{Introduction}

Breast cancer has the highest incidence rate and causes the second highest number of deaths among cancers in women according to cancer statistics from 2019 in the United States [1]. It is well accepted that postmastectomy radiotherapy (PMRT) improves long-term outcomes by reducing local recurrence and cancer mortality

\footnotetext{
* Correspondence: dryetian@126.com

+Lei Liu, Yongqiang Yang and Qi Guo contributed equally to this work. Department of Radiotherapy and Oncology, The Second Affiliated Hospital of Soochow University, Institute of Radiotherapy and Oncology of Soochow University, San Xiang Road No. 1055, Suzhou 215004, Jiangsu, China
}

in breast cancer after mastectomy $[2,3]$. The most recent National Comprehensive Cancer Network (NCCN) guidelines recommend the conventional fractionated radiotherapy (CFRT) schedule for PMRT, which consists of a total dose (TD) of 45.0 Gy to 50.4 Gy given in 25 to 28 fractions over 5 weeks or more and delivered to the chest wall and regional lymph nodes. However, with advances in radiotherapy technology, methods to reduce toxicity, overall treatment time and cost have gradually attracted the attention of researchers.

Previous reports indicate that breast cancer has a low ratio of $\alpha / \beta$ over the range of $2.0 \sim 4.0 \mathrm{~Gy}$, and this low $\alpha /$ 
$\beta$ ratio suggests that the efficacy of hypofractionated radiotherapy (HFRT) regimens are equivalent to CFRT in breast cancer [4]. Data from randomized controlled trials from the United Kingdom and Canada confirm this conclusion to a certain extent [5-11]. However, most of the patients in these trials were early breast cancer patients who underwent breast-conserving surgery. Adjuvant treatment of breast cancer after mastectomy remains controversial, and there are few relevant prospective randomized controlled clinical trials (RCTs) that address adjuvant treatment internationally. In Lancet Oncology, 2019, Wang et al. [12] report 5-year outcomes of a randomized, non-inferiority, open-label, phase 3 trial in China that compared postmastectomy HFRT with CFRT directed to the chest wall and the supraclavicular and level III axillary nodal regions in 820 patients with locally advanced breast cancer (at least four positive axillary lymph nodes). There were no significant differences in the 5-year cumulative incidence of locoregional recurrence, 5-year overall survival or 5-year disease-free survival between groups. Furthermore, acute and late toxicities were similar in both groups. This finding suggests that hypofractionated postmastectomy radiotherapy (HF PMRT) is safe and effective for patients with a high risk for breast cancer, exhibiting low toxicity and high local control rates. In addition, 15\% $(336 / 2236)$ and $8 \%(177 / 2215)$ of patients with postmastectomy HFRT were included in the START A and START B trials, respectively, and there was no significant difference in local recurrence or late toxicities between the two groups over a long-term follow-up of 10 years [5-8].

Clinically, HFRT could reduce the cost of cancer treatment, provide more convenient treatment and allow providers to treat more patients. There is growing interest in using the HF PMRT scheme, although the number of patients receiving HFRT after mastectomy in the United States is currently small (1.1\%) [13]. In recent years, HFRT use in patients who underwent breastconserving surgery has been written into NCCN and other treatment guidelines and has been gradually applied in the clinic, but using HFRT in patients after mastectomy remains controversial. Therefore, we aimed to use evidence-based medicine to compare the efficacy and toxicity of HFRT and CFRT after mastectomy.

\section{Methods}

\section{Study protocol}

A search of PubMed, EMBASE, Cochrane Library, Google Scholar, Wan Fang, and CNKI was conducted up through February 25, 2019. MeSH or Emtree terms combined free terms were used: "breast cancer", "mastectomy", "radiotherapy", "hypofractionated" and "conventional fractionated".

\section{Selection criteria}

Inclusion Criteria: (1) Surgical mastectomy in patients diagnosed with breast cancer by pathology. (2) Controlled trials comparing HFRT to CFRT after mastectomy. (3) Inclusion of study sample size $>20$ cases. (4) Complete information is provided in the literature. Exclusion Criteria: (1) Review articles, case reports, meeting abstracts, and lectures. (2) No clear diagnosis was made in enrolled patients. (3) Inclusion of study sample size $<20$ cases. (4) Incorrect data, incomplete data or unable to extract required data. (5) Duplicate publications.

\section{Data extraction}

Data were independently screened and extracted by two reviewers, including patient eligibility, study design, baseline characteristics, and number of events for all outcomes and interventions. Overall survival (OS) was the primary endpoint, and disease-free survival (DFS), locoregional recurrence (LRR), distant metastasis (DM), acute skin toxicity, acute lung toxicity, late skin toxicity, lymphedema, shoulder restriction, and late cardiac related toxicity were secondary endpoints. Any disagreement was resolved by consensus.

\section{Quality assessment}

Quality assessment of included studies was independently performed by two authors, and disagreements were resolved by consensus. Study quality was evaluated using the Newcastle-Ottawa scale (NOS). Primary evaluations included measurement of exposure factors, comparability between groups, and patient selection. Each study with NOS scores $\geq 6$ was considered a high-quality study, whereas studies with NOS scores $<6$ were considered low-quality studies. Quality assessment results of included studies are summarized in Table 1.

\section{Statistical analysis}

RevMan 5.3 analysis software (Cochrane Collaboration, Copenhagen, Denmark) and STATA 14.0 (Stata Corporation, College Station, TX, USA) were used for statistical analysis. Odds ratio (OR) and 95\% confidence interval $(95 \% \mathrm{CI})$ were used for count data. Cochran's Q test and $I^{2}$ statistics were used to assess heterogeneity between studies. If heterogeneity was not present $\left(P>0.1, I^{2}<50 \%\right)$, the fixed-effect model was adopted for analysis. Otherwise, a random-effect model was employed. The results are represented as forest maps, and potential heterogeneity was identified by sensitivity analysis. We assessed publication bias using the Egger test and funnel plots. $P<0.05$ was considered statistically significant. 


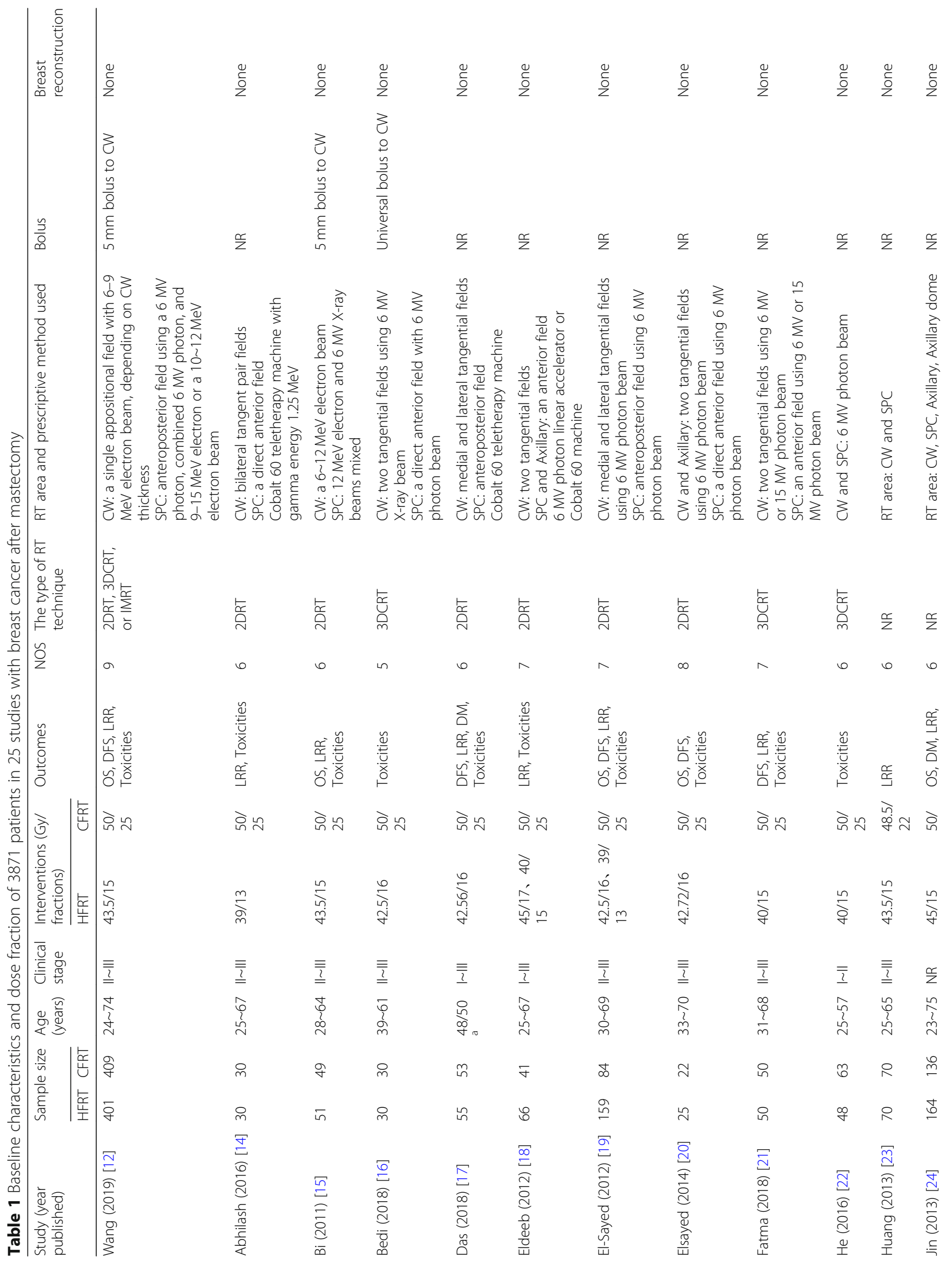




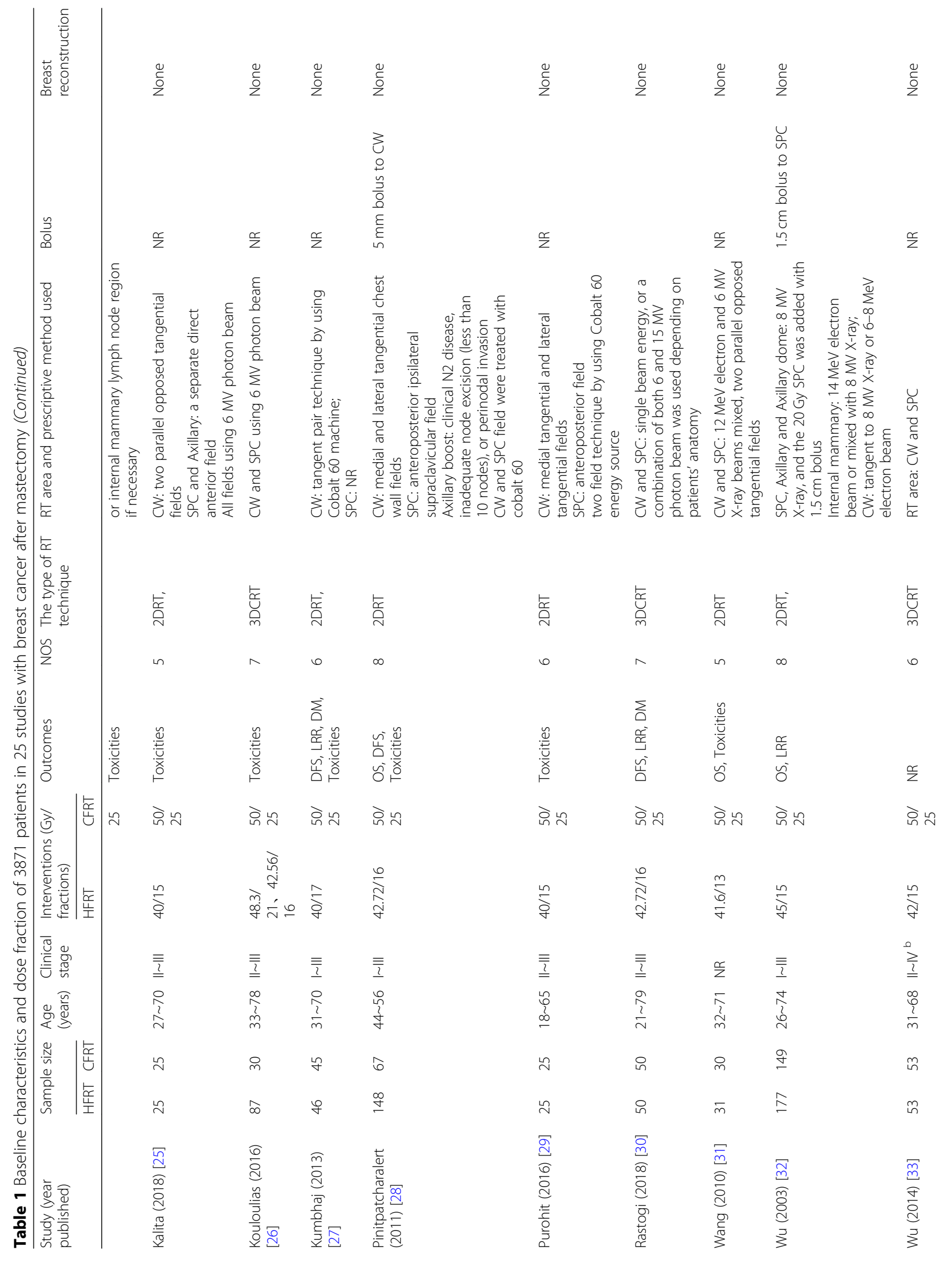




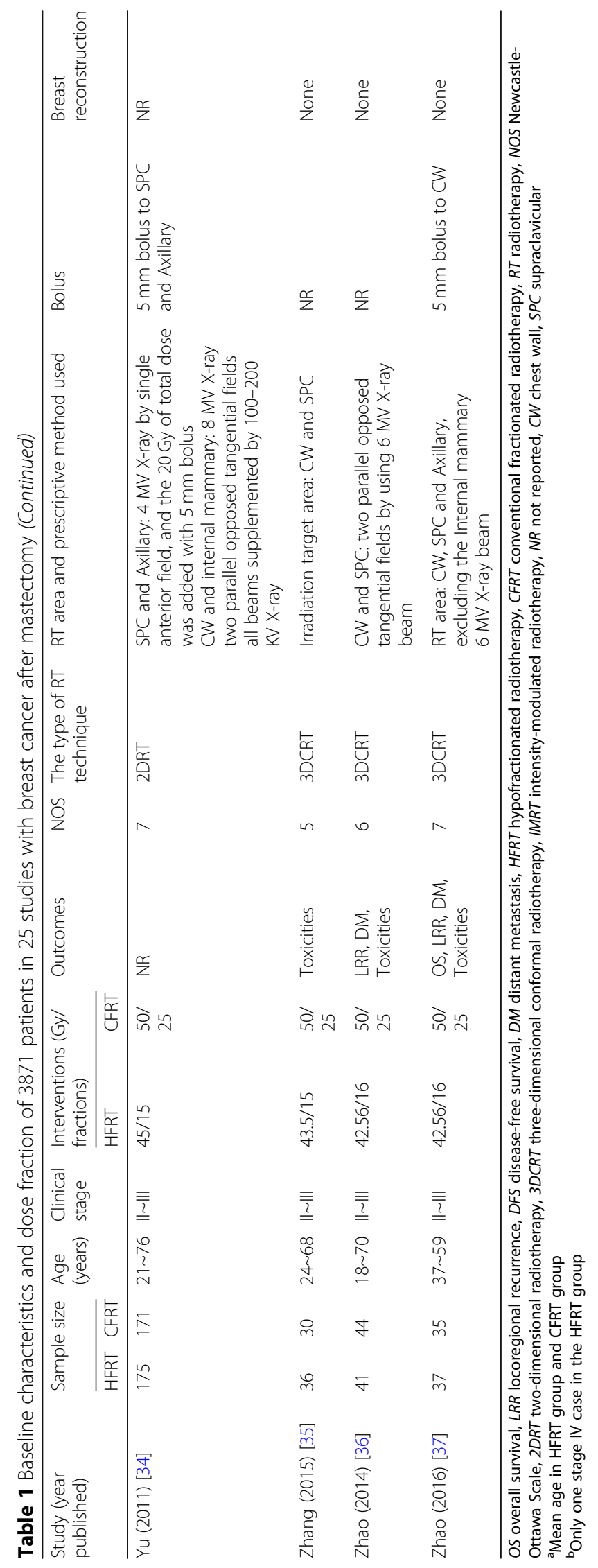




\section{Results}

\section{Study selection}

Two hundred twelve articles were initially retrieved, and after screening according to inclusion and exclusion criteria, 25 articles were entered into the systematic review [12, 14-37] (Fig. 1). Only 1 study was an RCT [12], and the rest were retrospective studies [14-37].

\section{Study characteristics}

The characteristics of the trials are summarized in Table 1. Studies were published in 2003-2019, with a total of 3871 patients with breast cancer, including 2080 in the HFRT group and 1791 in the CFRT group. All patients underwent mastectomy with potential differences in quality between study surgeries, and none receive breast reconstruction (except the study by $\mathrm{Yu}$ [34] not reported). Radiation treatment area generally included the ipsilateral side chest wall and or the ipsilateral side supraclavicular area [12, 14-37]. Eight studies [18, 20, 24, 25, 28, 32, 34, 37] proposed to add the axillary fossa, axillary dome or internal mammary lymph node region if necessary. $6 \mathrm{MV} \sim$ $8 \mathrm{MV} \mathrm{X}$-ray and $6 \mathrm{MeV} \sim 15 \mathrm{MeV}$ electron beams were generally used for radiation treatment, and fourteen trials $[12,14,15,17-20,25,27-29,31,32,34]$ used twodimensional radiotherapy technology, with cobalt 60 being used in some patients [14, 17, 18, 27, 29]. The median age ranged from 18 to 78 years, and the TD of radiotherapy in the HFRT group ranged from 39.0 to $48.3 \mathrm{~Gy}$, with a single dose of 2.3 to 3.2 Gy given over 13 to 17 fractions. The
TD in the CFRT group was $50.0 \mathrm{~Gy}$, with a single dose of 2.0 Gy over 25 treatments (only 1 trial [23] 48. 5 Gy in 22 fractions). Clinical characteristics between the two groups of patients included in the study, such as age, tumor stage, pathological type, estrogen and progesterone levels, HER2 status, chemotherapy regimen, etc., were not significantly different, so results were highly reliable. Patient information, including age, tumor stage, dose fraction, radiation therapy area, prescriptive method used, etc. is listed in Table 1. NOS scores are shown in Table 1.

\section{Meta-analysis outcomes}

In the combined overall survival rate, disease-free survival rate and distant metastasis rate, there were 2 studies [19, 28], 1 study [14] and 1 study [14], respectively, that could not be submitted to meta-analysis due to no events and were not included the corresponding study outcomes for analysis.

1. Overall Survival: Thirteen studies [12, 15, 18-21, 23, 24, 28, 31, 33, 34, 37] reported overall survival in 2646 patients, and results showed no significant difference between the two groups $(O R=1.08,95 \%$ $C I=0.87 \sim 1.33, P=0.49$, Fig. $2 \mathrm{a}$ ).

2. Disease-Free Survival: Ten studies [12, 14, 17, 19-21, $27,28,30,32$ ] reported disease-free survival in 2100 patients, and results showed no significant difference between the two groups $(O R=1.13,95 \% C I=$ $0.91 \sim 1.40, P=0.28$, Fig. $2 b)$.

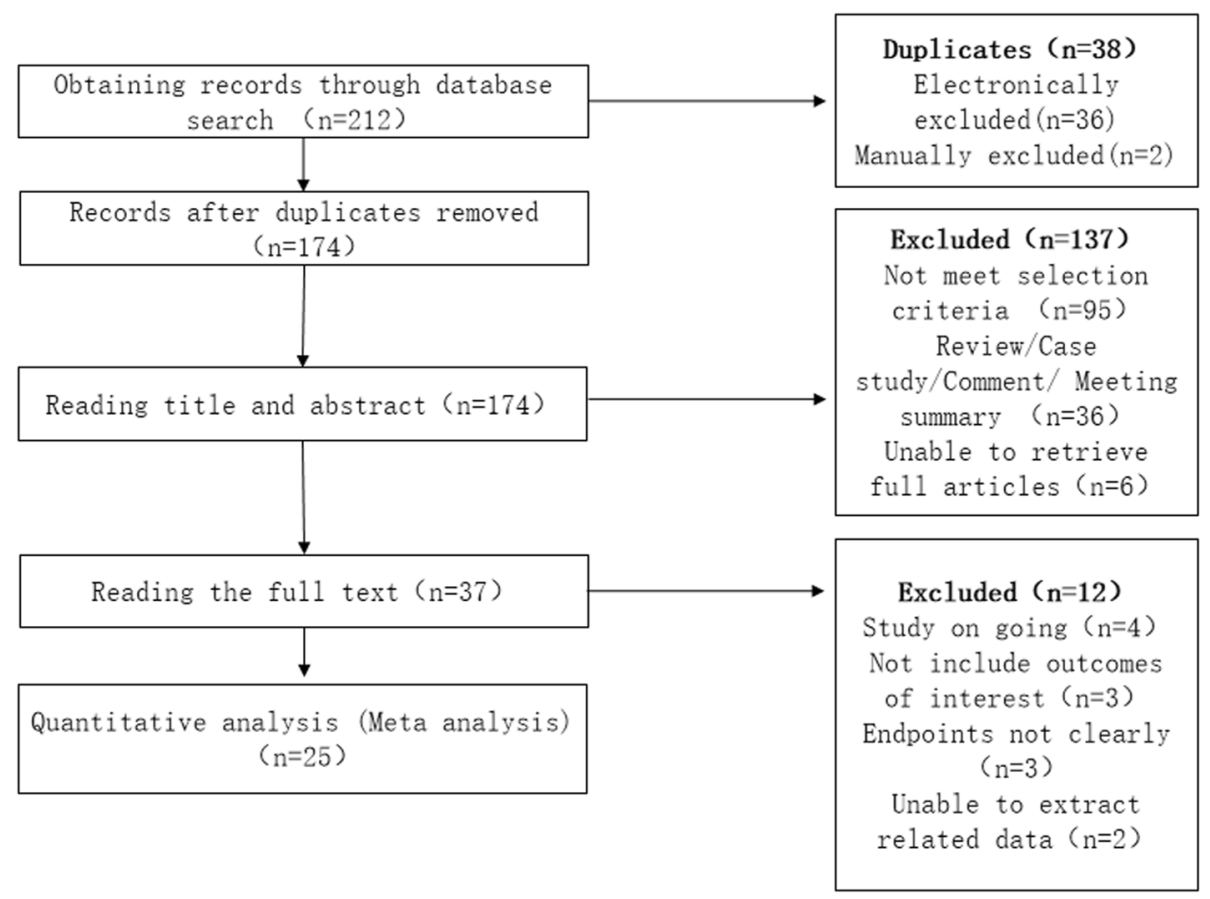

Fig. 1 Flow chart of the study selection process 


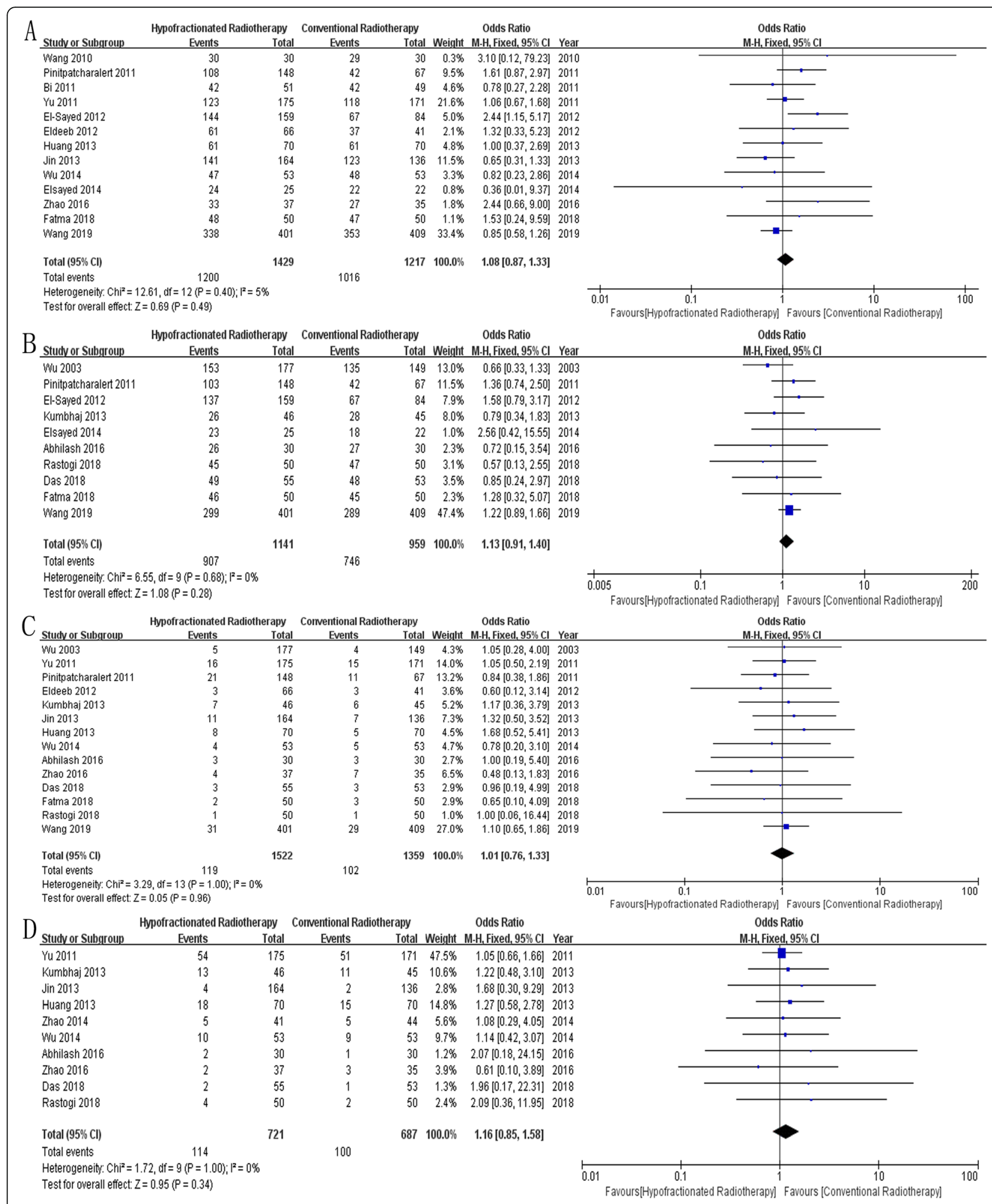

Fig. 2 Forest plot comparing the efficacy of HFRT with that of CFRT after mastectomy in breast cancer. a Overall Survival, b Disease-Free Survival, c Locoregional Recurrence, $\mathbf{d}$ Distant Metastasis 
3. Locoregional Recurrence: Fourteen studies [12, 14, $17,18,21,23,24,27,28,30,32-34,37]$ reported locoregional recurrence in 2881 patients, and results showed no significant difference between the two groups $(O R=1.01,95 \% C I=0.76 \sim 1.33, P=$ 0.96, Fig. 2c).

4. Distant Metastasis: Ten studies [14, 17, 23, 24, 27, $30,33,34,36,37$ ] reported distant metastasis in 1408 patients, and results showed no significant difference between the two groups $(O R=1.16,95 \%$ $C I=0.85 \sim 1.58, P=0.34$, Fig. 2d).

5. Acute Skin Toxicity: Twenty-three studies [12, 14$18,20-36]$ reported acute skin toxicity in 3456 patients, and results showed no significant difference between the two groups $(O R=0.94,95 \% C I=$ $0.67 \sim 1.32, P=0.72$, Fig. 3a).

6. Acute Lung Toxicity: Ten studies $[12,16,17,20$ $22,30,34-36$ ] reported acute lung toxicity in 1853 patients, and results showed no significant difference between the two groups (OR $=0.94,95 \%$ $C I=0.74 \sim 1.20, P=0.62$, Fig. 3b).

7. Late Skin Toxicity: Seven studies [12, 14, 17, 18, 26, 30, 31] reported late skin toxicity in 1363 patients, and results showed no significant difference between the two groups $(O R=0.98,95 \% C I=$ $0.75 \sim 1.27, P=0.88$, Fig. 3c).

8. Lymphedema: Nine studies [12, 16, 18, 21, 27-30, 34] reported lymphedema in 1801 patients, and results showed no significant difference between the two groups $(O R=0.99,95 \% C I=0.77 \sim 1.28, P=$ 0.94, Fig. 4a).

9. Shoulder Restriction: Four studies [12, 14, 17, 27] reported shoulder restriction in 1078 patients, and results showed no significant difference between the two groups $(O R=0.75,95 \% C I=0.43 \sim 1.31, P=$ 0.31, Fig. 4b).

10. Late Cardiac Related Toxicity: Six studies [12, 15, $23,28,34,35]$ reported late cardiac related toxicity

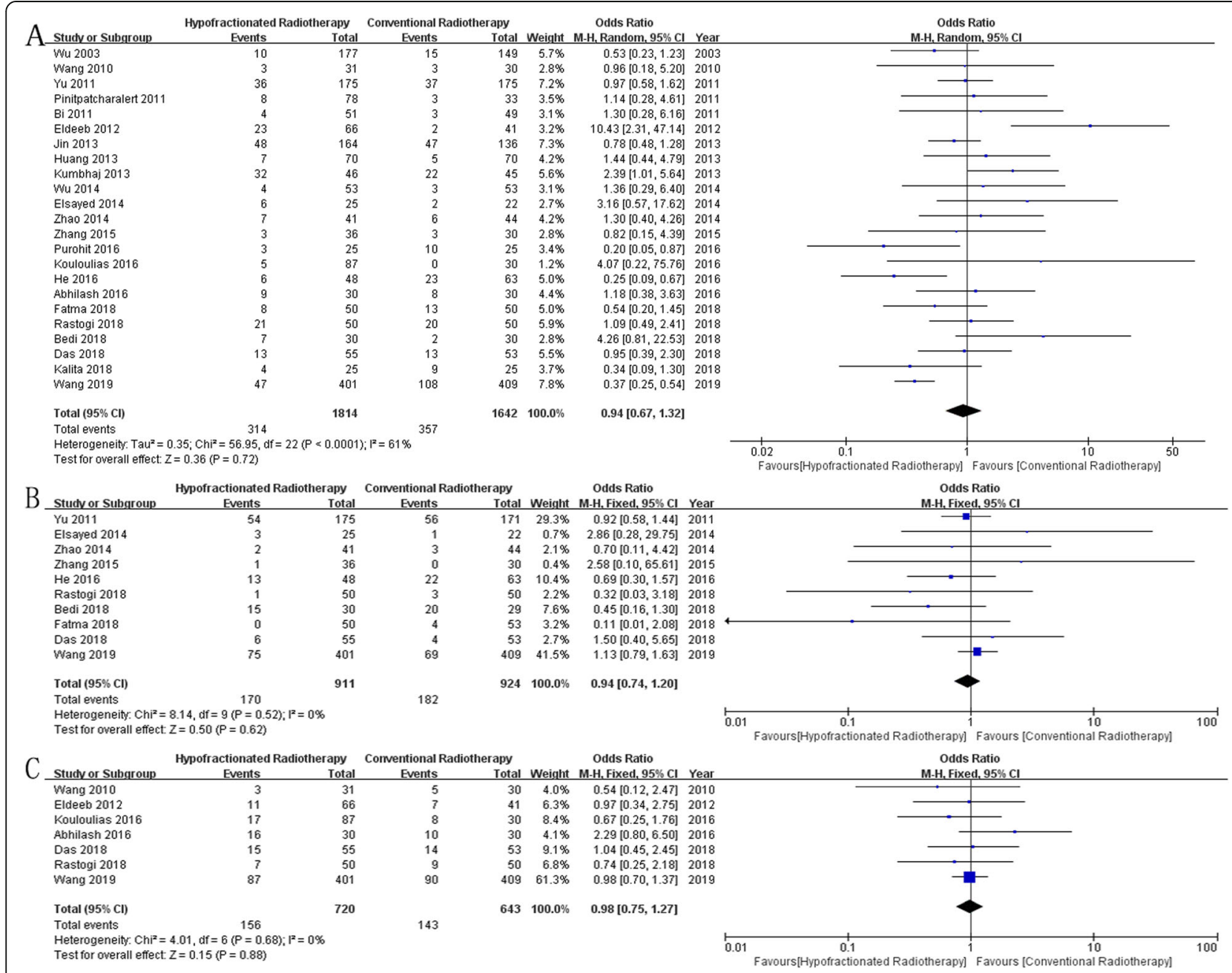

Fig. 3 Forest plot comparing the toxicity of HFRT with that of CFRT after mastectomy in breast cancer. a Acute Skin Toxicity, b Acute Lung Toxicity, c Late Skin Toxicity 


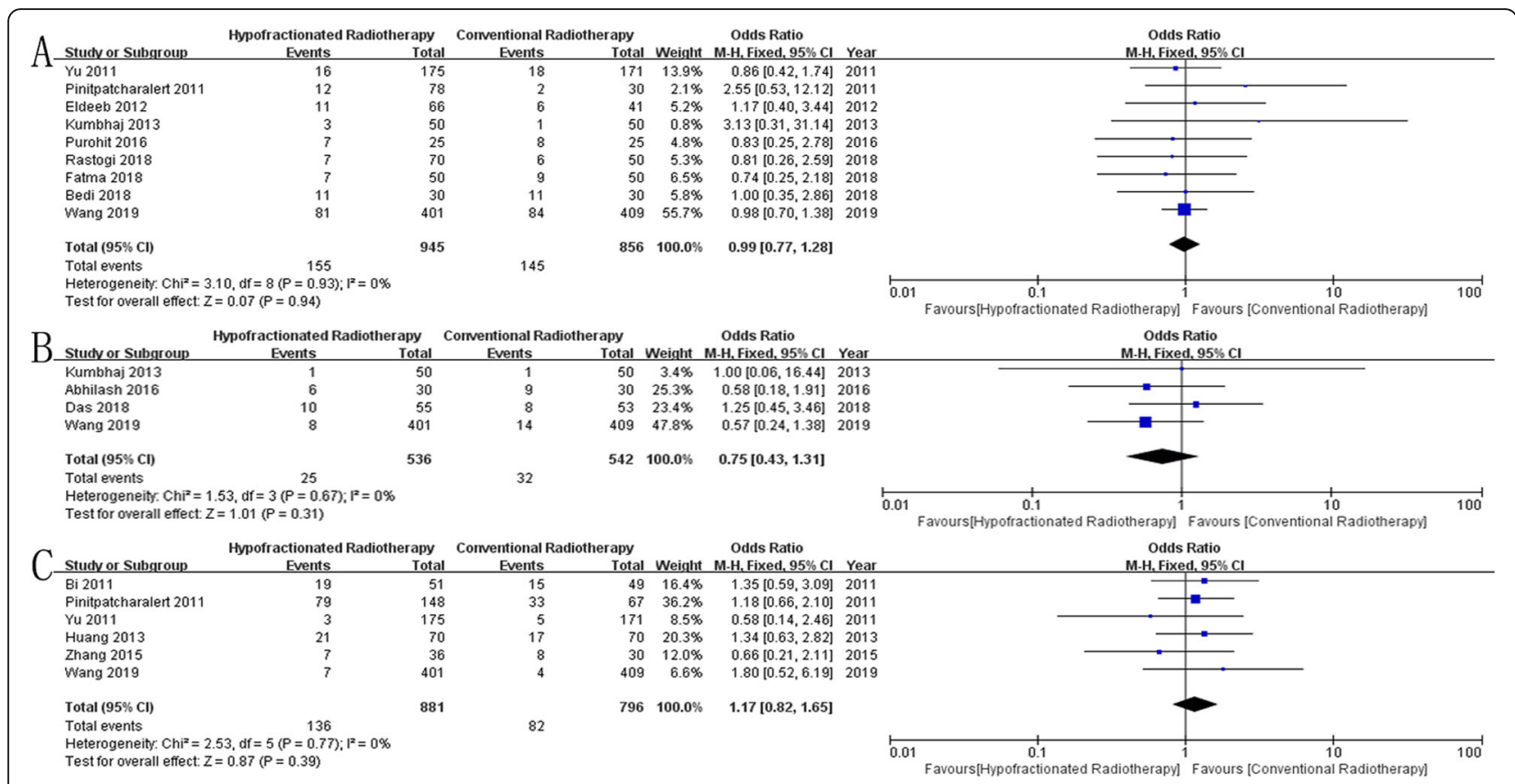

Fig. 4 Forest plot comparing the toxicity of HFRT with that of CFRT after mastectomy in breast cancer. a Lymphedema, b Shoulder Restriction, c Late Cardiac Related Toxicity

in 1677 patients, and results showed no significant difference between the two groups $(O R=1.17,95 \%$ $C I=0.82 \sim 1.65, P=0.39$, Fig. 4c).

\section{Heterogeneity analysis and publication Bias}

Study outcomes included overall survival, disease-free survival, locoregional recurrence, distant metastasis, acute lung toxicity, late skin toxicity, lymphedema, shoulder restriction and late cardiac related toxicity not present heterogeneity $\left(P>0.1, I^{2}<50 \%\right)$, and a fixedeffect model was adopted for analysis. The study outcome acute skin toxicity presented heterogeneity $(P<$ $0.1, I^{2}>50 \%$ ), and a random-effect model was employed. Meanwhile, sensitivity analysis of this study outcome did not find any abnormal studies, indicating that our research results are more stable. Further analysis of other study outcomes using sensitivity analysis did not observe significant heterogeneity (Fig. 5, Fig. 6). Publication bias results suggest that study outcome of acute skin toxicity has a published bias $(P<0.05)$, but there was no significant bias in the remaining study outcomes $(P>0.05)$ (Table 2, Fig. 7, Fig. 8).

\section{Discussion}

For patients who underwent breast-conserving surgery and received whole-breast radiotherapy, long-term results from large randomized trials confirmed equivalent efficacy and safety of HFRT and CFRT. However, for patients who underwent surgical mastectomy the scarcity of high-level evidence has resulted in only a few patients having received HFRT [13], and only one randomized study has compared HFRT and CFRT in breast cancer patients who underwent mastectomy [12]. Other evidence for the clinical application of postmastectomy HFRT schedule has until now only been available from case series, retrospective studies, or subgroup analyses from the START randomized trials. Thus, we performed this meta-analysis to determine the efficacy and safety of postmastectomy HFRT schedule on outcomes in women with breast cancer. This meta-analysis indicated that HFRT and CFRT were equally effective with respect to overall survival (OS), disease-free survival (DFS), locoregional recurrence (LRR), and distant metastasis (DM) after breast mastectomy.

In recent small retrospective cohort studies, HF PMRT was shown to be effective with acceptable toxicity [38-41]. In a recent phase 2 trial [42], 67 women with clinical stage II to IIIa breast cancer who received a HF PMRT regimen of 36.6 Gy over 11 fractions to the chest wall and the draining regional lymph nodes with a scar boost of 4 fractions of 3.33 Gy revealed that after a median follow-up of 32 months, patients with isolated ipsilateral chest wall tumor recurrences were $3.0 \%$, the 3-year estimated overall survival was $92.0 \%$ (95\% CI, 78.9 97.1), the 3year estimated local recurrence-free survival was 89.2\% (95\% CI, 74.8 95.6), the 3-year estimated distant recurrence-free survival was $90.3 \% \quad(95 \%$ CI, 79.7 95.6), and low toxicity was reported. In Lancet Oncology, 2019, Shu-Lian Wang [12] reports 5-year 


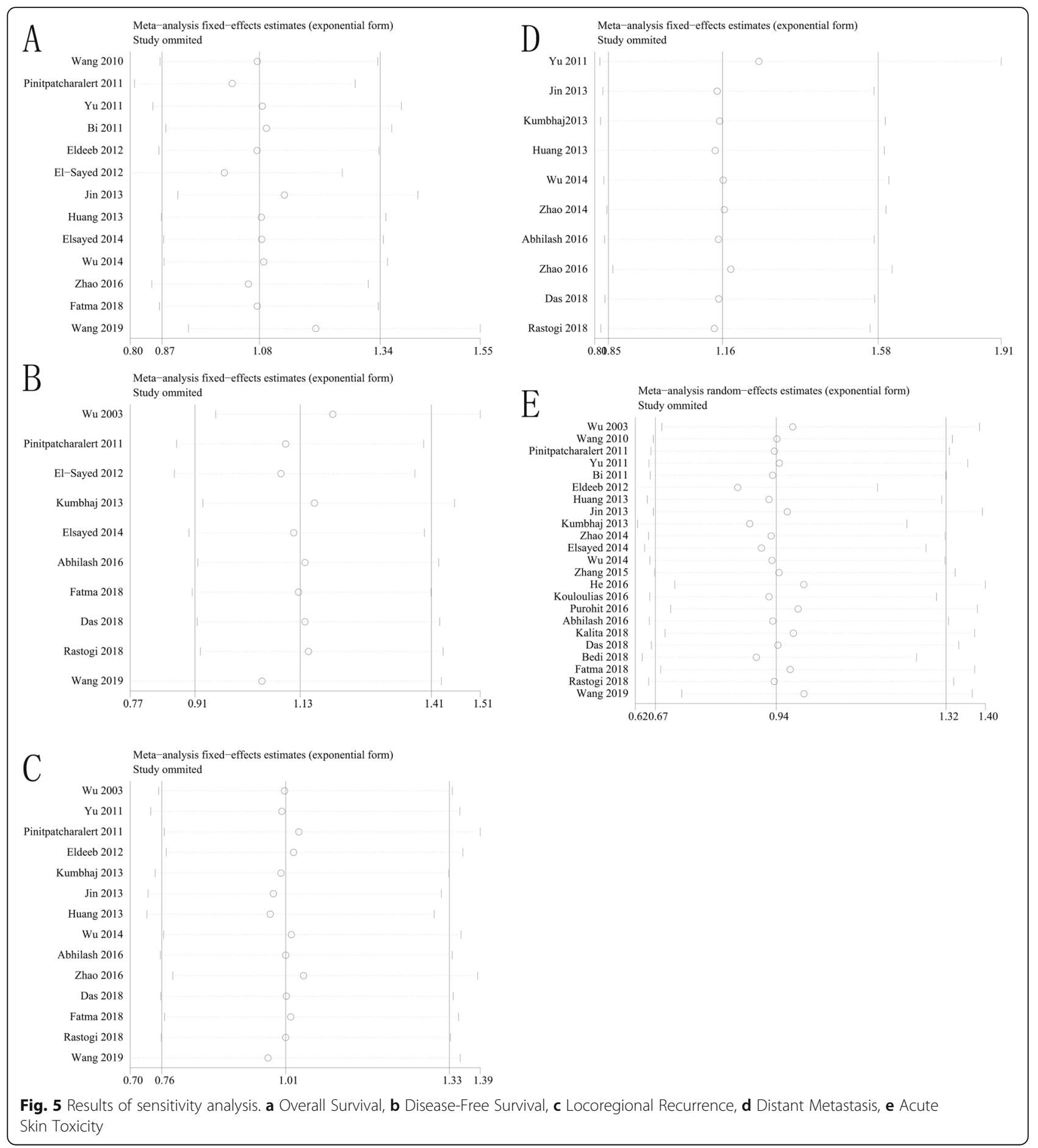

outcomes of a randomized, non-inferiority, open-label, phase 3 trial comparing postmastectomy HFRT $(43.5$ Gy over 15 fractions in 3 weeks) and CFRT (50 Gy over 25 fractions in 5 weeks) directed to the chest wall and the supraclavicular and level III axillary nodal region in 820 patients with locally advanced breast cancer (at least four positive axillary lymph nodes or T3-4 tumors). All patients underwent chemotherapy, $76.5 \%$ used hormonal therapy, and the primary endpoint was 5-year locoregional recurrence. After a median follow-up of 58.5 months, there were no significant differences in the 5 -year cumulative incidence of locoregional relapse $\quad\left(8.3 \% \quad\left[\begin{array}{lll}90 \% & C I\end{array}\right.\right.$ 5.8 10.7] VS 8.1\% [5.4 10.6]), 5-year overall survival (84\%[90\% CI 80 88] VS 86\% [82 89]) and 5-year disease-free survival $(74 \%$ [95\% CI $70 \sim 79]$ VS $70 \%$ 


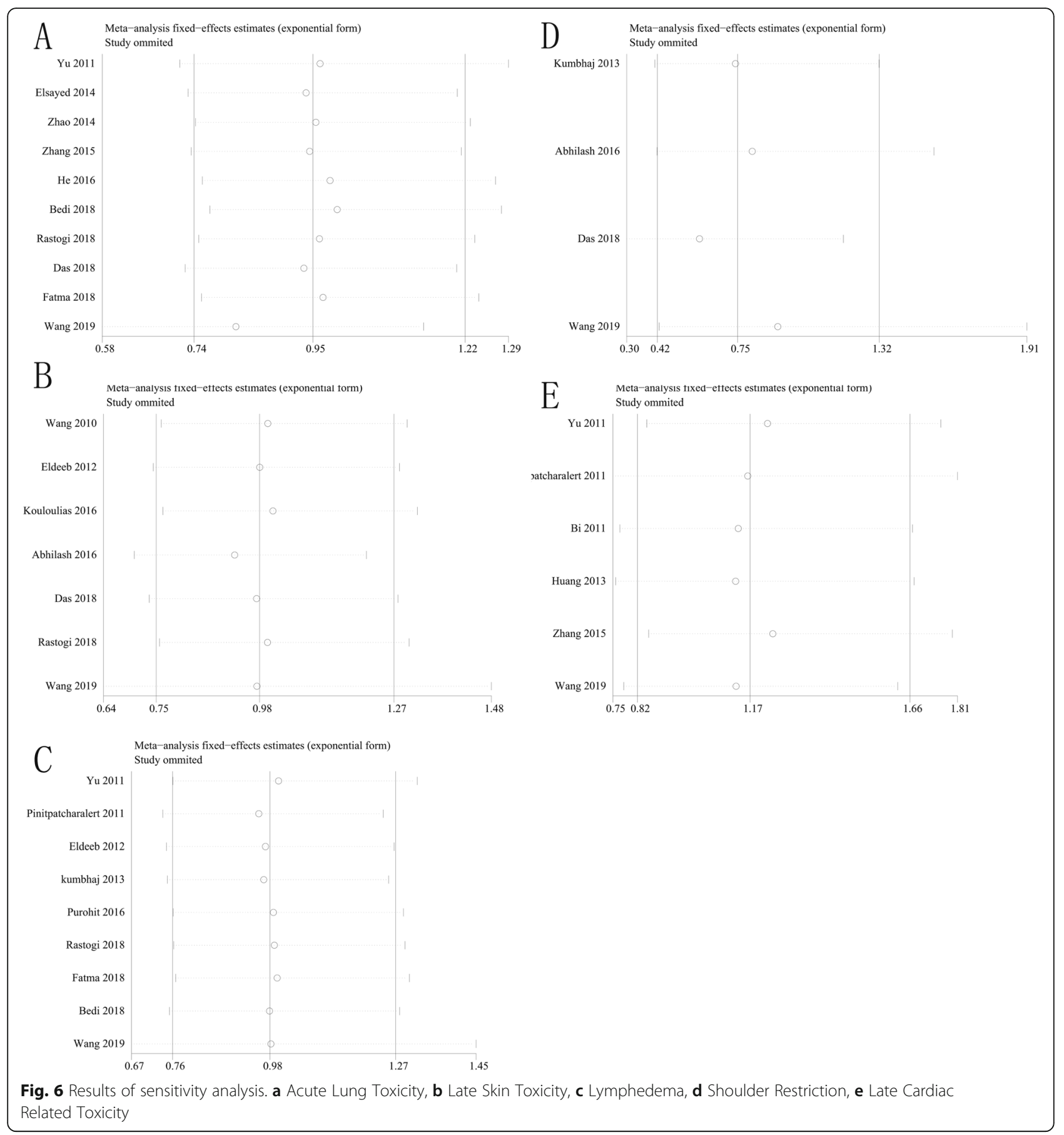

[65 76]) between the HFRT and CFRT groups. Furthermore, there was no significant difference between the two groups in the incidence of acute or late toxicities, including symptomatic radiation pneumonitis, lymphedema, ischemic heart disease, late skin toxicity, lung fibrosis or shoulder dysfunction; however, fewer patients experienced grade 3 acute skin toxicity in the HFRT group than in the CFRT group (14 [3\%] of 401 patients VS 32 [8\%] of 409 patients, $p<0.0001)$. No brachial plexopathy or rib fractures were observed, and frequencies of lymphedema and shoulder dysfunction were also reassuringly low, at less than $1 \%$ of grade 2 toxicity for both events. These results suggest that the HF PMRT regimen is safe and effective for patients with high-risk breast cancer, with low toxicity and high local control rate [12].

For long-term survival of breast cancer patients, the late treatment toxicities are also important. The results 
Table 2 Results of publication bias

\begin{tabular}{llllll}
\hline Study Outcome & Coefficient & Standard Error & $t$ & $P>|t|$ & $95 \%$ Confidence Interval \\
\hline Overall Survival & 0.42 & 0.56 & 0.74 & 0.47 & $-0.82 \sim 1.66$ \\
Disease-Free Survival & -0.43 & 0.53 & -0.82 & 0.44 & $-1.64 \sim 0.78$ \\
Locoregional Recurrence & -0.39 & 0.33 & -1.19 & 0.26 & $-1.11 \sim 0.33$ \\
Distant Metastasis & 0.42 & 0.25 & 1.67 & 0.13 & $-0.16 \sim 1.00$ \\
Acute Skin Toxicity & 1.57 & 0.64 & 2.45 & 0.02 & $0.24 \sim 2.89$ \\
Acute Lung Toxicity & -0.50 & 0.49 & -1.01 & 0.34 & $-1.63 \sim 0.64$ \\
Late Skin Toxicity & -0.15 & 0.67 & -0.23 & 0.83 & $-1.86 \sim 1.55$ \\
Lymphedema & 0.41 & 0.38 & 1.07 & 0.32 & $-0.50 \sim 1.32$ \\
Shoulder Restriction & 0.39 & 1.30 & 0.30 & 0.79 & $-5.19 \sim 5.98$ \\
Late Cardiac Related Toxicity & -0.89 & 0.97 & -0.92 & 0.41 & $-3.59 \sim 1.80$
\end{tabular}

of this study found that there were no differences in acute skin toxicity, acute lung toxicity, late skin toxicity, lymphedema, shoulder restriction, or late cardiac related toxicity between the two groups. And we also found that no grade $2 / 3 / 4$ late lung toxicity patients were observed, and the incidence of grade 1 was very low in the included studies [12, 14, 15, 23, 28, 32, 35]. Further, the randomized trial result showed that late lung toxicity may be increased in patients after HFRT $(P=0.08)$, but it was not statistically significant, which is worthy of further follow-up and research. Many studies have shown that the incidence of grade 2-4 acute skin toxicity after HF PMRT is between 10 and 25\% [12, 28, 38, 39, 42], and this meta-analysis showed that the incidence of grade $2-4$ acute skin toxicity in 3456 patients across 23 trials was $17.3 \%$, which in line with reported rates. Similar results were observed in the PMRT subgroup of the UK START study $(12 \%, 513 / 4451)$, which compared to the CFRT group, there was no significant difference in lymphedema or moderate or marked breast/shoulder/ arm symptoms, etc. in patients receiving HFRT $[5,6]$. Another late toxicity that should be considered is cardiac-related toxicity in patients after HFRT. Previous studies have shown that the incidence of cardiovascular events in patients with breast cancer after radiotherapy is very low, and the use of HFRT was not observed to increase that risk compared to CFRT [43-45]. The 10-year follow-up results of the UK START studies revealed that fatal cardiac events in START A and START B were 1.3 and $0.5 \%$, respectively, while the incidence of ischemic heart disease was low $(0.7 \%)$, and there was no significant difference between these two groups [5]. The proportion of patients with the late cardiac related toxicity was higher $(52.1 \%)$ in the Pinitpatcharalert [28] study that the meta-analysis indicated, with $3.0 \%(1 / 67)$ in the CFRT group and $3.0 \%(3 / 148)$ in the HFRT group

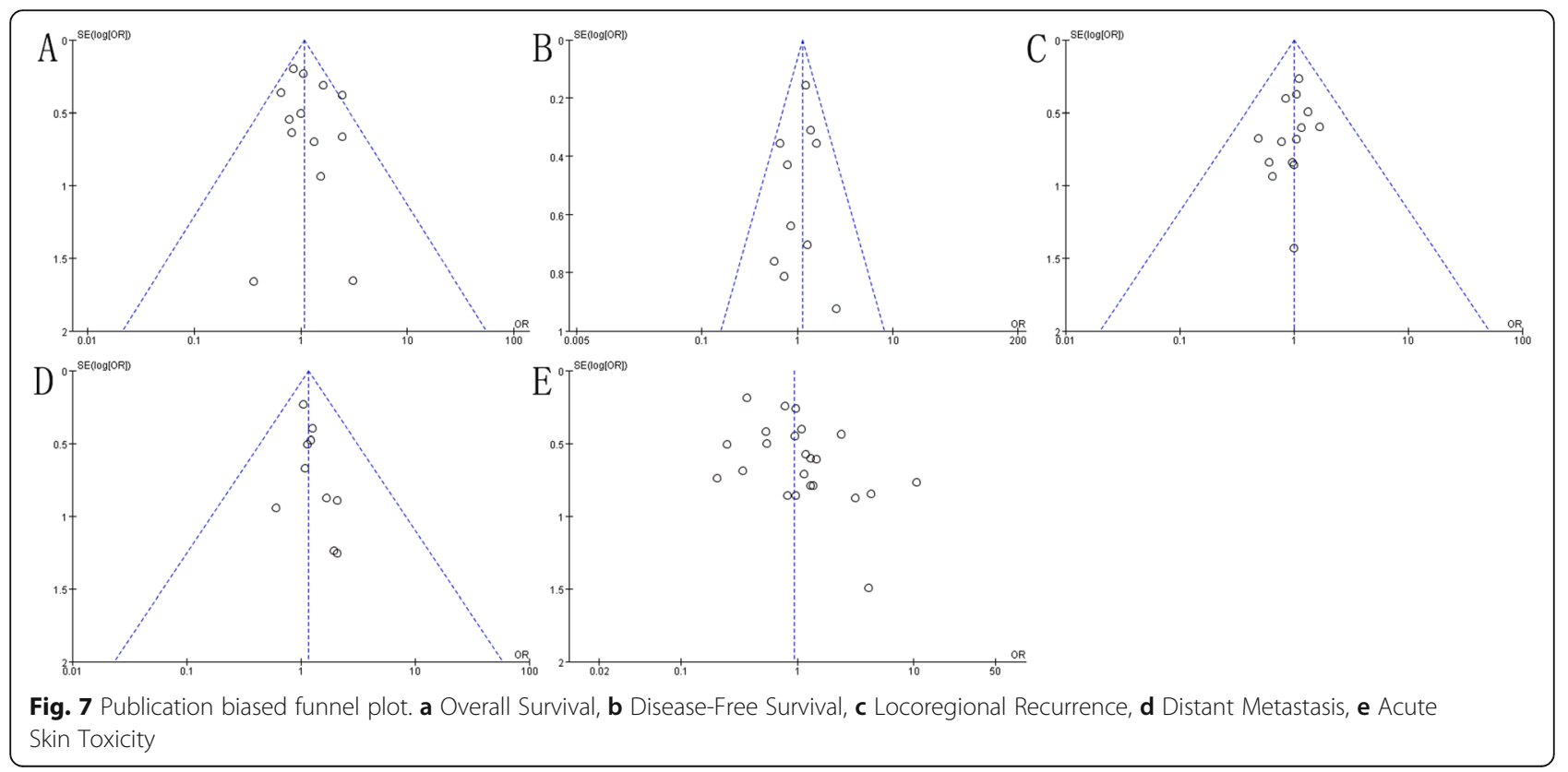




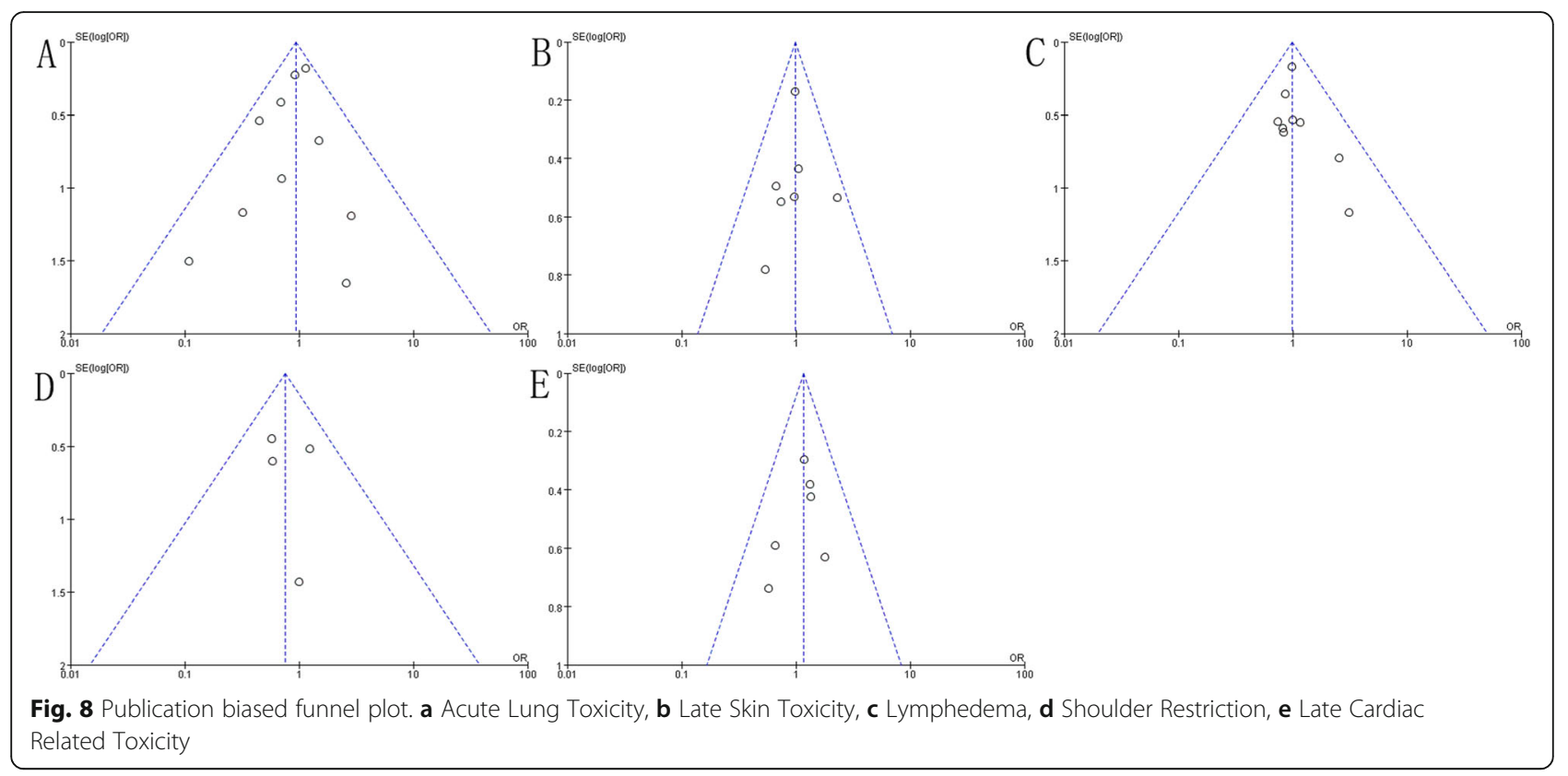

reporting patient deaths from cardiovascular events. This proportion is higher than in previous studies, which may be due to the small number of patients included, but there was no statistically significant difference between these two groups. The meta-analysis in our study showed no significant differences in late cardiac-related toxicity between the two groups, consistent with the above findings, indicating that HFRT does not significantly increase the risk of cardiovascular related events in breast cancer patients.

A higher dose per treatment fraction might increase the risk of toxicities in the setting of regional nodal irradiation (RNI) [46], but hypofractionated RNI was not observed to increase toxicity in one randomized clinical trial [12]. Two recent studies reported that the efficacy and safety of hypofractionated RNI were acceptable [47, 48]. One was based on UK START trials, with 864/5861 patients who experienced adjuvant lymphatic radiotherapy (LNRT) (PMRT 202/864, 23.4\%) assessed using the EORTC QLQ-BR23 scale, protocol-specific questions and by physicians [47]. The long-term results from START trials suggest that appropriately dosed hypofractionated LNRT is safe, according to patient and physician-assessed arm and shoulder symptoms, a conclusion consistent with the findings for $>2.0 \mathrm{~Gy}$ schedules delivered to the breast/chest wall [47]. Another retrospective study reviewed 257 patients with stage IIa to IIIc breast cancer receiving hypofractionated RNI, with $80.2 \%$ patients having PMRT, 99.6\% undergoing chemotherapy, 81.3\% having hormonal treatment, and $25.3 \%$ having anti-HER2 targeted therapy. The median follow-up time was 64 months (range, 11 to 88 months), and the 5-year OS, DFS, locoregional recurrence (LRR)-free survival, and distant metastasis (DM)-free survival was 86.6, 84.4, 93.9 and 83.1\%, respectively. During study follow-up, no acute symptomatic pneumonitis, cardiac events, brachial plexopathy or rib fractures occurred, and the incidence of grade 2-4 lymphedema was $5.8 \%$ [48]. The above findings suggest that the HFRT schedule may be acceptable in breast cancer patients who require RNI. However, prospective trials are necessary to confirm these results.

Hypofractionated radiotherapy could help to contain the costs of cancer care by mitigating financial toxicity and can be performed in most radiotherapy centers, even at small-scale hospitals. Studies have reported that the cost of using hypofractionated whole breast irradiation (WBI) in the United States is $31.7 \%$ lower than that of conventional fractionated WBI [49], and one study in Asia also indicated that the total cost of treatment for hypofractionated WBI compared to conventional fractionated WBI was reduced by about one-third [50]. It should be noted that although hypofractionated PMRT is not the same as the target area irradiated by hypofractionated WBI, the treatment technique and radiotherapy fraction are similar, and it can still shorten the treatment cycle, reduce the time of patient trips to the hospital, and save medical resources, which is more cost-effective. This issue is even more important in lowand middle-income countries.

The inclusion and exclusion criteria of this study were strict, the literature search was comprehensive, and the results are highly credible, but the following limitations do exist: 1. Quality of the included studies was unequal, and the number of included studies was limited. There 
may be differences in the quality of surgery between studies, and the quality of surgery could not be evaluated. There are many methods for adjuvant treatment of breast cancer, and all adjuvant treatments could not be evaluated. 2. Included studies did not provide survival data for patients of different age, tumor stage, positive lymph node numbers, pathological type, estrogen/progesterone levels, and could not be further analyzed for their impact on efficacy. However, the clinical characteristics of the two groups of patients included in the study, including age, tumor stage, pathological type, estrogen and progesterone levels, HER2 status, postoperative chemotherapy, etc., were not significantly different, so the reliability of these results was still high. 3. Most of the current studies were retrospective (only one was an $\mathrm{RCT}$ ), and the quality of research methods is unequal. There are differences in treatment methods, radiotherapy, loss of follow-up descriptions, etc. It is difficult to extract all treatment data and then evaluate them. 4. Some trials used outdated radiotherapy techniques, and the use of hypofractionation schedules is variable. 5 . Limited follow-up times in these included trials, multicenter prospective clinical trials and long-term follow-up are still needed for verification.

\section{Conclusions}

The results of this study show that there is no statistically significant difference in efficacy or toxicity between hypofractionated radiotherapy and conventional fractionated radiotherapy after breast mastectomy. Hypofractionated radiotherapy is a safe and effective radiotherapy schedule, but the current study is still primarily retrospective and requires large-scale randomized clinical trials to confirm this conclusion along with long-term follow-up of patients who experience late toxicities.

\section{Abbreviations}

CFRT: Conventional fractionated radiotherapy; DFS: Disease-free survival; DM: Distant metastasis; HF PMRT: Hypofractionated postmastectomy radiotherapy; HFRT: Hypofractionated radiotherapy; LNRT: Lymphatic radiotherapy; LRR: Locoregional recurrence; NCCN: National Comprehensive Cancer Network; NOS: Newcastle-Ottawa scale; OR: Odds ratio; OS: Overall survival; PMRT: Postmastectomy radiotherapy; RCTs: Randomized controlled clinical trials; RNI: Regional nodal irradiation; TD: Total dose; WBI: Whole breast irradiation

\section{Acknowledgements}

Not applicable.

\section{Authors' contributions}

$L L, Y Y$ and QG conceived and coordinated the study; designed, performed, and analyzed the experiments; and wrote the manuscript. BR, QP, LZ and YZ collected and analyzed the data. YT revised the manuscript. All authors reviewed the results and approved the final version of the manuscript.

\section{Funding}

This study was sponsored and funded by the Jiangsu Medical Innovation Team (No. CXDT-37) and Medicine Outstanding Leader of Suzhou (No. 62).
Availability of data and materials

All data generated or analysed during this study are included in this published article [and its supplementary information files].

Ethics approval and consent to participate

Not applicable.

Consent for publication

Not applicable.

Competing interests

The authors declare that they have no competing interests.

Received: 23 October 2019 Accepted: 7 January 2020

Published online: 17 January 2020

References

1. Siegel RL, Miller KD, Jemal A. Cancer statistics, 2019 [J]. CA Cancer J Clin. 2019;69(1):7-34. https://doi.org/10.3322/caac.21551.

2. Mcgale $\mathrm{P}$, Taylor C, Correa $\mathrm{C}$, et al. Effect of radiotherapy after mastectomy and axillary surgery on 10-year recurrence and 20-year breast cancer mortality: meta-analysis of individual patient data for 8135 women in 22 randomised trials [J]. Lancet. 2014;383(9935):2127-35. https://doi.org/10. 1016/S0140-6736(14)60488-8.

3. Clarke M, Collins R, Darby S, et al. Effects of radiotherapy and of differences in the extent of surgery for early breast cancer on local recurrence and 15year survival: an overview of the randomised trials[J]. Lancet. 2005;366(9503): 2087-106. https://doi.org/10.1016/S0140-6736(05)67887-7.

4. Qi X, White J, Li X. Is a/ $\beta$ for breast cancer really low? An analysis of large randomized clinical trials for radiation therapy of breast cancer[J]. Int J Radiat Oncol Biol Phys. 2009;75(3):S146. https://doi.org/10.1016/j.jjrobp.2009. 07.345.

5. Haviland J, Owen J, Dewar J, et al. The UK standardisation of breast radiotherapy (START) trials of radiotherapy hypofractionation for treatment of early breast cancer: 10-year follow-up results of two randomised controlled trials [J]. Lancet Oncol. 2013;14(11):1086-94. https://doi.org/10. 1016/s1470-2045(08)70077-9.

6. Hopwood P, Haviland JS, Sumo G, et al. Comparison of patient-reported breast, arm, and shoulder symptoms and body image after radiotherapy for early breast cancer: 5-year follow-up in the randomised standardisation of breast radiotherapy (START) trials[J]. Lancet Oncol. 2010;11(3):231-40. https://doi.org/10.1016/S1470-2045(09)70382-1.

7. Bentzen SM, Agrawal RK, Aird EG, et al. The UK standardisation of breast radiotherapy (START) trial a of radiotherapy hypofractionation for treatment of early breast cancer: a randomised trial[]]. Lancet Oncol. 2008;9(4):331-41. https://doi.org/10.1016/S1470-2045(08)70077-9.

8. Bentzen SM, Agrawal RK, Aird EG, et al. The UK standardisation of breast radiotherapy (START) trial B of radiotherapy hypofractionation for treatment of early breast cancer: a randomised trial[J]. Lancet. 2008;371(9618):1098107. https://doi.org/10.1016/S0140-6736(08)60348-7.

9. Whelan T, Mackenzie R, Julian J, et al. Randomized trial of breast irradiation schedules after lumpectomy for women with lymph node-negative breast cancer[J]. J Natl Cancer Inst. 2002;94(15):1143-50. https://doi.org/10.1093/ jnci/94.15.1143.

10. Yarnold J, Ashton A, Bliss J, et al. Fractionation sensitivity and dose response of late adverse effects in the breast after radiotherapy for early breast cancer: long-term results of a randomised trial[J]. Radiother Oncol. 2005; 75(1):9-17. https://doi.org/10.1016/.r.radonc.2005.01.005.

11. Owen JR, Ashton A, Bliss JM, et al. Effect of radiotherapy fraction size on tumour control in patients with early-stage breast cancer after local tumour excision: long-term results of a randomised trial[J]. Lancet Oncol. 2006;7(6): 467-71. https://doi.org/10.1016/S1470-2045(06)70699-4.

12. Wang SL, Fang H, Song YW, et al. Hypofractionated versus conventional fractionated postmastectomy radiotherapy for patients with high-risk breast cancer: a randomised, non-inferiority, open-label, phase 3 trial[]]. Lancet Oncol. 2019;20(3):352-60. https://doi.org/10.1016/S1470-2045(18)30813-1.

13. Venigalla S, Guttmann DM, Jain V, et al. Trends and patterns of utilization of hypofractionated postmastectomy radiotherapy: a national cancer database analysis [J]. Clinical Breast Cancer. 2018;18(5):e899-908. https://doi.org/10. 1016/j.clbc.2018.02.009. 
14. Abhilash GH, Dhull AK, Atri R, et al. Comparison of hypofractionated radiation therapy versus conventional radiation therapy in post mastectomy breast cancer[J]. J Evid Based Med Healthc. 2016;3(26):1177-81. https://doi. org/10.18410/jebmh/2016/270

15. Bi LP, Li YJ, Gong XH, et al. Clinical study of hypofractionated radiotherapy in breast cancer after modified radical mastectomy[J]. J Clin Med Practice. 2011;15(13):21-3. https://doi.org/10.3969/j.issn.1672-2353.2011.13.007.

16. Bedi N, Yadav HP, Banipal RPS, Aggarwal S, Gupta Y. Hypofractionated radiotherapy in breast cancer: Is it safe?[J]. HECS Int J Comm Health Med Res. 2018;4(4):47-53. https://doi.org/10.21276/ijchmr.

17. Das P, Das TK, Jana A, et al. Comparison of result and outcome of conventional and hypofractionated radiotherapy in post-operative breast cancer patients[J]. Int J Med Sci Public Health. 2018;7(6):452-6. https://doi. org/10.5455/ijmsph.2018.0102010032018.

18. Eldeeb H, Awad I, Elhanafy O. Hypofractionation in post-mastectomy breast cancer patients: seven-year follow-up[J]. Med Oncol. 2012;29(4):2570-6. https://doi.org/10.1007/s12032-012-0192-1.

19. El-Sayed MI, AbdelWanis ME. Comparison of hypofractionated and conventional radiotherapy protocols in breast cancer patients: a retrospective study[J]. J Cancer Sci Ther. 2012;4(6):158-63. https://doi.org/10. 4172/1948-5956.1000132

20. Elsayed MA, Magdy KAA. Post-mastectomy hypofractionation radiotherapy in breast cancer patients[J]. Cancer and Oncology Research. 2014;2(7):87-93. https://doi.org/10.13189/cor.2014.020701.

21. Fatma MFA, Khater A. Hypofractionated versus conventionally fractionated radiotherapy in post-mastectomy breast Cancer patients[J]. Journal of Cancer Therapy. 2018;9:941-54. https://doi.org/10.4236/jct.2018.911078.

22. He HL, Liu HM, Xu SK, et al. Acute adverse reactions of hypofractionated and conventional fractionated radiotherapy in patients after radical mastectomy[J]. Int Med Health Guidance News. 2016;22(5):625-8. https:// doi.org/10.3760/cma.j.issn.1007-1245.2016.05.010.

23. Huang J. The effect of hypofractionated radiotherapy and conventional fraction radiotherapy in local advanced breast cancer patients after radical mastectomy [J]. Yiayao Qianyan. 2013;16:158-9. https://doi.org/10.3969/j.issn. 2095-1752.2013.16.163

24. Jin XY, Duan QY. Compare the treatment effect of radiotherapy with different fractionated doses in post-mastectomy[J]. Sichuan Med J. 2013; 34(1):106-8. https://doi.org/10.3969/j.issn.1004-0501.2013.01.048.

25. Kalita AK, Bhattacharyya M, Jagtap VK, et al. Radiotherapy in Post Mastectomy High Risk Breast Cancer: Early results of a Prospective Study comparing Conventional versus Hypofractionated Radiotherapy[J]. J Med Sci Clin Res. 2018;06(07):743-51. https://doi.org/10.18535/jmscr/v6i7.125.

26. Kouloulias $V$, Mosa E, Zygogianni A, et al. A retrospective analysis of toxicity and efficacy for 2 Hypofractionated irradiation schedules versus a conventional one for post-mastectomy adjuvant radiotherapy in breast Cancer[J]. Breast Care. 2016;11(5):328-32. https://doi.org/10.1159/000449433.

27. Kumbhaj $P$, Sharma $R$, Saini $P$, et al. A study of two different dose fractionation schedules of post mastectomy Chest Wall irradiation in carcinoma breast patients[J]. Int J Med Sci Public Health. 2013;2(4):1001-5. https://doi.org/10.5455/ijmsph.2013.040820131.

28. Pinitpatcharalert A, Chitapanarux I, Euathrongchit J, et al. A retrospective study comparing hypofractionated radiotherapy and conventional radiotherapy in postmastectomy breast cancer[J]. J Med Assoc Thail. 2011; 94(Suppl 2):S94-102. https://doi.org/10.1016/j.ijrop.2011.9.029.

29. Purohit $\mathrm{R}$, Sharma $\mathrm{N}$, Sharma $\mathrm{N}$, et al. Comparison of acute toxicities in conventional and hypofractionated radiotherapy in post-mastectomy breast cancer[]]. J Med Sci Clin Res. 2016;04(06):10721-4. https://doi.org/10.18535/jmscr/v4i6.07.

30. Rastogi $K$, Jain $S$, Bhatnagar AR, et al. A comparative study of hypofractionated and conventional radiotherapy in postmastectomy breast cancer patients[J]. Asia Pac J Oncol Nurs. 2018;5(1):107-13. https://doi.org/ 10.4103/apjon.apjon_46_17

31. Wang Z, Gong MY, Zeng LZ, et al. The short-term curative effects and adverse effects of hypofractionated postoperative radiotherapy for breast cancer[J]. World Health Digest. 2010;07(23):109-11. https://doi.org/10.3969/j. issn.1672-5085.2010.23.098.

32. Wu JX, Hui ZG, Li YX, et al. Post-mastectomy radiotherapy with different fractionated dose schemes in early breast cancer[J]. Chin J Oncol. 2003; 25(3):285-8. https://doi.org/10.3760/j.issn:0253-3766.2003.03.023.

33. Wu EW, Xing AM, Zhao J, et al. Comparison of the effects of hypofractionated radiotherapy and conventional radiotherapy after radical mastectomy for breast cancer[J]. Prac J Med \& Pharm. 2014;31(1):34-5.
34. Yu ZL, Zhao JG, Zhang BZ, et al. Research on the long-term efficacy of different irradiation methods for postoperative breast cancer[J]. Inner Mongolia Med J. 2011;43(12):1414-7. https://doi.org/10.3969/j.issn.10040951.2011.12.003.

35. Zhang W. Comparative analysis of radiotherapy toxicity of conventional fractionation and larger fractionation after breast cancer modified radical surgery[J]. Chinese Community Doctors. 2015;31(29):81-3. https://doi.org/10. 3969/j.issn.1007-614x.2015.29.52.

36. Zhao SH, Cao XM, Liu GQ, et al. Clinical trial of postmastectomy hypofractionation radiotherapy in breast cancer[J]. J Modern Oncol. 2014; 22(9):2120-3. https://doi.org/10.3969/j.issn.1672-4992.2014.09.36.

37. Zhao XB, Ren GS. Analysis of radiotherapy optimization regimens after modified radical mastectomy[J]. Eur Rev Med Pharmacol Sci. 2016;20(22): 4705-9.

38. Ko DH, Norriss $\mathrm{A}$, Harrington $\mathrm{CR}$, et al. Hypofractionated radiation treatment following mastectomy in early breast cancer: the Christchurch experience[J]. J Med Imaging Radiat Oncol. 2015;59(2):243-7. https://doi.org/10.1111/17549485.12242

39. Koukourakis MI, Panteliadou M, Abatzoglou IM, et al. Postmastectomy hypofractionated and accelerated radiation therapy with (and without) subcutaneous amifostine cytoprotection[J]. Int J Radiat Oncol Biol Phys. 2013;85(1):e7-13. https://doi.org/10.1016/j.jirobp.2012.08.017.

40. Doré M, Cutuli B, Cellier $P$, et al. Hypofractionated irradiation in elderly patients with breast cancer after breast conserving surgery and mastectomy: analysis of 205 cases[J]. Radiat Oncol. 2015;10(1):161. https:// doi.org/10.1186/s13014-015-0448-y.

41. Chatterjee $S$, Arunsingh M, Agrawal S, et al. Outcomes following a moderately Hypofractionated adjuvant radiation (START B type) schedule for breast Cancer in an unscreened non-Caucasian population[J]. Clin Oncol. 2016;28(10):e165-72. https://doi.org/10.1016/j.clon.2016.05.008.

42. Khan AJ, Poppe MM, Goyal S, et al. Hypofractionated postmastectomy radiation therapy is safe and effective: first results from a prospective phase II trial[J]. J Clin Oncol. 2017:35(18):2037-43. https://doi.org/10.1200/JCO.2016.70.7158.

43. Chan EK, Woods R, McBride ML, et al. Adjuvant Hypofractionated versus conventional whole breast radiation therapy for early-stage breast Cancer: long-term hospital-related morbidity from cardiac causes[J]. Int J Radiat Oncol Biol Phys. 2014;88(4):786-92. https://doi.org/10.1016/j.jirobp.2013.11.243.

44. Stokes EL, Tyldesley S, Woods R, et al. Effect of nodal irradiation and fraction size on cardiac and cerebrovascular mortality in women with breast Cancer treated with local and Locoregional radiotherapy[J]. Int J Radiat Oncol Biol Phys. 2011;80(2):403-9. https://doi.org/10.1016/j.jirobp.2010.02.041.

45. Marhin W, Wai E, Tyldesley S. Impact of fraction size on cardiac mortality in women treated with tangential radiotherapy for localized breast Cancer[]]. Int J Radiat Oncol Biol Phys. 2007;69(2):483-9. https://doi.org/10.1016/j. ijrobp.2007.03.033

46. Vinh-Hung V, Nguyen NP, Verschraegen C. Hypofractionated nodal irradiation for breast cancer: a case for caution[J]. JAMA Oncol. 2019;5(1):134. https://doi.org/10.1001/jamaoncol.2018.5061.

47. Haviland JS, Mannino M, Griffin C, et al. Late normal tissue effects in the arm and shoulder following lymphatic radiotherapy: results from the UK START (standardisation of breast radiotherapy) trials[J]. Radiother Oncol. 2018;126(1):155-62. https://doi.org/10.1016/j.radonc.2017.10.033.

48. Bellefqih S, Elmajjaoui S, Aarab J, et al. Hypofractionated regional nodal irradiation for women with node-positive breast Cancer[J]. Int J Radiat Oncol Biol Phys. 2017;97(3):563-70. https://doi.org/10.1016/j.jirobp.2016.11.010.

49. Greenup RA, Camp MS, Taghian AG, et al. Cost comparison of radiation treatment options after lumpectomy for breast cancer[J]. Ann Surg Oncol. 2012;19(10):3275-81. https://doi.org/10.1245/s10434-012-2546-5.

50. Karasawa K, Kunogi H, Hirai T, et al. Comparison of hypofractionated and conventionally fractionated whole-breast irradiation for early breast cancer patients: a single-institute study of 1,098 patients[J]. Breast Cancer. 2014; 21(4):402-8. https://doi.org/10.1007/s12282-012-0406-6.

\section{Publisher's Note}

Springer Nature remains neutral with regard to jurisdictional claims in published maps and institutional affiliations. 